\title{
Intestinal digestibility of long-chain fatty acids in lactating dairy cows: A meta-analysis and meta-regression
}

\author{
J. P. Boerman, ${ }^{*}$ J. L. Firkins, $†$ N. R. St-Pierre, $†$ and A. L. Lock* \\ *Department of Animal Science, Michigan State University, East Lansing 48824 \\ †Department of Animal Sciences, The Ohio State University, Columbus 43210
}

\begin{abstract}
The objective of this analysis was to examine the intestinal digestibility of individual long-chain fatty acids (FA) in lactating dairy cows. Available data were collated from 15 publications containing 61 treatments, which reported total and individual FA duodenal flows and calculations of intestinal digestibility. All studies involved lactating dairy cows, and estimates of digestibility were based on measurements either between the duodenum and ileum (18 treatments) or between the duodenum and feces (43 treatments). Fatty acid digestibility was calculated for C16:0, C18:0, C18:1 (cis and trans isomers), C18:2, and C18:3. Digestibility of C18:0 was lower than for $\mathrm{C} 18: 1$ and $\mathrm{C} 18: 3$, with no difference in digestibility between saturated FA (C16:0 and $\mathrm{C} 18: 0)$. We weighted the studies by the reciprocal of the variance to generate best-fit equations to predict individual FA digestibility based on duodenal flow of FA and dietary independent variables. The flow of C18:0 negatively affected the digestibility of C18:0 and was also included in the best-fit equations for all other 18-carbon FA using duodenal flow characteristics. The type of fat supplemented had an effect on digestibility of individual FA, with whole seeds having reduced digestibility. Our meta-analysis results showed minimal differences in the digestibility of individual FA. However, C18:0 flow through the duodenum had a negative effect on the digestibility of several individual FA, with the largest negative effect on C18:0 digestibility. The mechanisms that reduce $\mathrm{C} 18: 0$ absorption at high concentrations are unknown and warrant further investigation.
\end{abstract}

Key words: fatty acid, digestibility, meta-analysis

\section{INTRODUCTION}

Digestion and metabolism of FA in ruminants has gained interest from both a research and industry

\footnotetext{
Received March 18, 2015.

Accepted July 21, 2015.

${ }^{1}$ Corresponding author: allock@msu.edu
}

perspective due to several factors. First, dietary FA supplements have been used to increase the ME density of rations in lactating dairy cattle (Jenkins and Jenny, 1989; Chilliard, 1993). Depending on stage of lactation and energy balance, an increase in ME density could increase milk production, milk fat yield, and body reserves as long as dietary FA supplements do not reduce DMI or negatively affect the digestibility of other nutrients. Second, increased recognition of the bioactive properties of specific FA has led to increased interest in fat supplementation in ruminant diets. For example, supplemented n-3 FA improved reproductive performance in early lactation animals (Abayasekara and Wathes, 1999; Ambrose et al., 2006) and C16:0 supplementation improved milk fat yield compared with C18:0 supplementation (Rico et al., 2014b). Third, basal diets can vary dramatically in FA profile and content; therefore, research on FA digestion and metabolism is important even when no supplemental fat is included in diets. The ability to understand and model FA digestibility will be useful for diet formulation strategies and provide information for optimal FA supplementation.

Metabolism of FA begins in the rumen through the processes of hydrolysis and biohydrogenation. Hydrolysis occurs when triglycerides and glycolipids are converted into glycerides and FA by microbial lipases (Jenkins, 1993). Unsaturated FA, which are toxic to certain rumen microbes, undergo biohydrogenation to form saturated FA (Jenkins et al., 2008; Maia et al., 2010). Because of these changes in the rumen, feed-to-feces digestibility estimates for individual FA, appropriate for nonruminants, are not applicable for ruminants. The FA available for absorption in the small intestine are similar to those leaving the rumen (Moore and Christie, 1984). This consists of approximately 80 to $90 \%$ free FA with the remainder components of microbial phospholipids plus small amounts of dietaryderived triglycerides and glycolipids, which are hydrolyzed by intestinal and pancreatic lipases (Doreau and Ferlay, 1994). The low $\mathrm{pH}$ of the digesta entering the duodenum and the high concentration of taurocholic acid in bile promote the solubility of FA (Harrison and 
Leat, 1975). Pancreatic and bile secretions are added to the digesta in the duodenum, and are responsible for solubilizing FA (Bauchart, 1993). Pancreatic and bile secretions are at an apparent steady state in ruminants and not subject to large fluctuations dependent on meal composition (Noble, 1981). Most absorption of FA occurs in the jejunum; therefore, to accurately measure the digestibility of individual FA, duodenal flows of FA are needed to determine the total amount of each FA available to the ruminant. Fatty acids may also become biohydrogenated in the large intestine (Pantoja et al., 1996), which may result in an overprediction of apparent unsaturated FA digestibility and an underprediction of saturated FA digestibility. Therefore, differences may be present in digestibility estimates when digesta samples are collected from the ileum compared with feces.

Previous reports have indicated that the digestibility of saturated FA decreases with increasing chain length and unsaturation increases digestibility of FA (Steele and Moore, 1968; Andrews and Lewis, 1970). Digestibility of FA might decrease as more fat is included in the diet (Palmquist, 1991; Weisbjerg et al., 1992). Specifically, the reduction in digestibility as fat is included in diets has been linked to the lower digestibility of C18:0 (Weisbjerg et al., 1992). Based on previous reports of differences in long-chain FA digestibility and the importance of correctly modeling FA to understand the metabolism of FA in dairy cows, our objective was to perform a meta-analysis to determine apparent intestinal digestibility of individual long-chain FA in lactating dairy cattle. Secondarily, our objective was to use meta-regression to evaluate whether digestibility estimates of individual FA differed dependent on specific individual FA, FA concentration, and other potential biological drivers.

\section{MATERIALS AND METHODS}

Our initial selection criteria for inclusion into the data set were studies that reported individual FA digestibility measurements in lactating dairy cows using duodenally cannulated cows. We collected data from 20 studies representing 80 treatment means that were published in peer-reviewed journals. Five studies were removed because no estimates of variation were reported; an estimate of variation is required to properly weight the studies (Borenstein et al., 2009). Of the remaining 15 studies with 62 treatments, one treatment was removed because it contained saturated triglycerides as partially hydrogenated tallow (Pantoja et al., 1996), which has been previously reported as poorly digested in ruminants (Elliott et al., 1996; Weiss and Wyatt, 2004). The 61 remaining treatment means included 46 containing supplemental fat and 16 containing no supplemental fat source. Table 1 provides information on the individual studies and treatments used in the data set. Treatments were separated into categories based on supplemental fat type; control diets (no supplemental fat added) and diets supplemented with animal-vegetable fat, calcium-salts of FA, tallow, vegetable oil, seed meal, whole seeds, and other.

Comprehensive Meta-Analysis v 2.0 software was used to analyze the data (Biostat, Englewood, NJ). Apparent digestibility estimates were obtained using a MIXED model, which accounted for variation both within and among studies. Studies were weighted based on the inverse of the sum of both the within and among study variance. Digestibility of C18:0 was used as the comparison with all other FA because of equal saturation compared with $\mathrm{C} 16: 0$ and equal chain length compared with C18:1, C18:2, and C18:3. If digestibility estimates were reported for individual isomers of unsaturated FA, a weighted average of digestibility based on flow through the duodenum was used. For example, if both cis and trans isomers of C18:1 were reported, we combined the data to represent a single value for $\mathrm{C} 18: 1$ digestibility.

Our data set included digestibility estimates from both ileal and fecal collections. Using fecal digestion does not account for biohydrogenation and possible synthesis of FA from microbes that could occur in the large intestine. Only 4 studies with 18 treatment comparisons used ileally cannulated cows to measure FA digestibility in the small intestine. Therefore, we further examined if site of collection affected digestibility estimates for individual FA by evaluating studies that used similar methods of collection together.

Figures of study-adjusted values for digestibility of FA were developed based on SAS code described by St-Pierre (2001). Including the random effect of study in the model accounts for variation among studies and improves the accuracy of equations produced.

Meta-regression was used to determine dietary variables or measurements taken from the duodenum that influence digestibility estimates using JMP version 10.0.2 (SAS Institute Inc., Cary, NC). Studies were weighted by the inverse of the standard error squared (St-Pierre, 2001; Borenstein et al., 2009). In studies from which the standard error was less than half of the mean standard error, the standard error was set to half of the mean standard error across all studies to prevent over weighting (Firkins et al., 2001). The original model including all variables for duodenal flow was 
Table 1. Description of studies included in the analysis

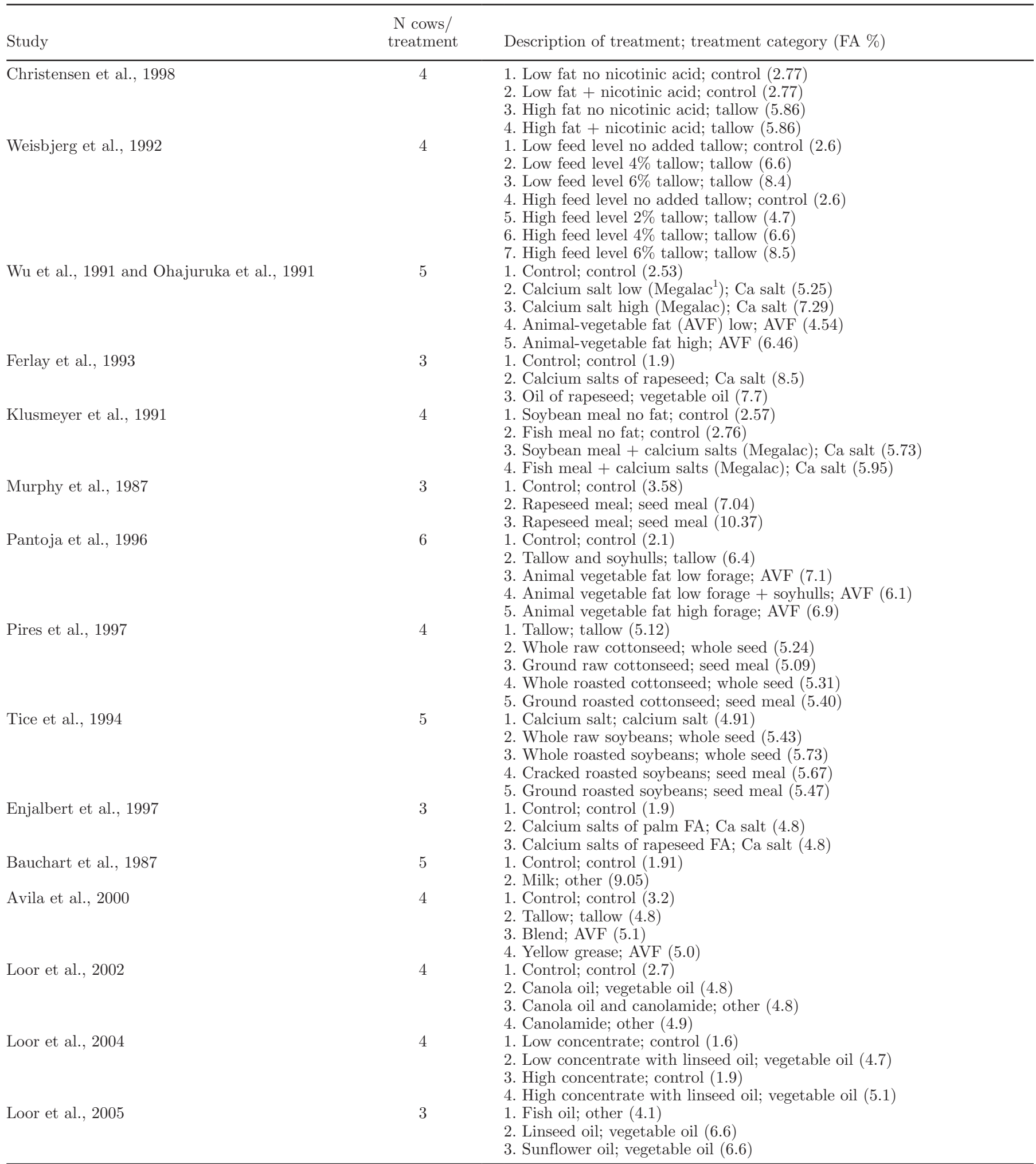

${ }^{1}$ Calcium salt of palm FA (Church \& Dwight Inc., Princeton, NJ). 


$$
\begin{aligned}
\mathrm{Y}= & \beta_{0}+\text { Study }+\beta_{1} \text { Total FA Flow }(\mathrm{g} / \mathrm{d})+\beta_{2} \mathrm{C} 16: 0 \\
& (\% \text { of FA })+\beta_{3} \mathrm{C} 16: 0^{2}(\% \text { of FA })+\beta_{4} \mathrm{C} 18: 0 \\
& (\% \text { of } \mathrm{FA})+\beta_{5} \mathrm{C} 18: 0^{2}(\% \text { of } \mathrm{FA})+\beta_{6} \mathrm{C} 18: 1 \\
& (\% \text { of } \mathrm{FA})+\beta_{7} \mathrm{C} 18: 1^{2}(\% \text { of } \mathrm{FA})+\beta_{8} \mathrm{C} 18: 2 \\
& (\% \text { of } \mathrm{FA})+\beta_{9} \mathrm{C} 18: 2^{2}(\% \text { of } \mathrm{FA})+\beta_{10} \mathrm{C} 18: 3 \\
& (\% \text { of } \mathrm{FA})+\beta_{11} \mathrm{C} 18: 3^{2}(\% \text { of } \mathrm{FA})+\text { error }
\end{aligned}
$$

where the individual FA are percent of total FA flow through the duodenum.

The original model including all dietary variables was

$$
\begin{gathered}
\mathrm{Y}=\beta_{0}+\text { Study }+\beta_{1} \mathrm{DMI}(\mathrm{kg} / \mathrm{d})+\beta_{2} \mathrm{DMI}^{2}(\mathrm{~kg} / \mathrm{d}) \\
+\beta_{3} \text { Forage }(\% \text { of diet })+\beta_{4} \text { Forage }^{2}(\% \text { of diet }) \\
+\beta_{5} \mathrm{DMI}(\mathrm{kg} / \mathrm{d}) \times \text { Forage }(\% \text { of diet })+\beta_{6} \mathrm{C} 16: 0 \\
(\% \text { of diet DM })+\beta_{7} \mathrm{C} 18: 0(\% \text { of diet DM }) \\
+\beta_{8} \mathrm{C} 18: 1(\% \text { of diet DM })+\beta_{9} \mathrm{C} 18: 2(\% \text { of diet DM }) \\
+\beta_{10} \mathrm{C} 18: 3(\% \text { of diet DM })+\beta_{11} \mathrm{FA} \text { in } \mathrm{Y}^{2} \\
(\% \text { of diet } \mathrm{DM})+\beta_{12} \mathrm{DMI}(\mathrm{kg} / \mathrm{d}) \times \mathrm{FA} \text { in } \mathrm{Y} \\
(\% \text { of diet DM })+\beta_{13} \text { Forage }(\% \text { of diet }) \times \mathrm{FA} \text { in Y } \\
(\% \text { of diet DM })+\text { Fat type }+ \text { error. }
\end{gathered}
$$

where FA in $\mathrm{Y}$ would correspond to the FA digestibility that is being estimated. For example, if $\mathrm{Y}=\mathrm{C} 16: 0$ digestibility, then $\mathrm{FA}$ in $\mathrm{Y}=\mathrm{C} 16: 0$ as percent of diet DM.

Variables were removed from the model using backward elimination with significance criteria of $P<0.05$. For models that included significant interactions or quadratic terms, the linear terms remained in the model regardless of significance (St-Pierre, 2001). The random effect of study was included in the model and digestibility estimates were weighted by the inverse of the standard error term squared to improve the accuracy of the model. Collinearity of significant variables was measured by the variance inflation factor. Variables were considered highly correlated when the variance inflation factor was $>10$ and removed from the model as explained by St-Pierre and Glamocic (2000). Inclusion of the random effect of study improves the accuracy of the final model, but using those solutions for predictions for future studies underestimates error for those predictions unless one accounts for the uncertainty surrounding the realized future study effect. Therefore, previous researchers typically reported RMSE (the square root of the estimated residual variance) and CV from models with the study effect and again without the random effect of study (Oldick et al.,
1999). However, this approach is not strictly appropriate because the estimated fixed effects are not the same for the 2 types of models. In the current report, what previously would have been termed RMSE is now reported as $\hat{\sigma}_{e}$ (estimated $\sigma$ for error), and this statistic was divided by the mean of the dependent variable and multiplied by 100 to calculate an equivalent to the traditional CV. From the same set of covariance parameter estimates, the square root of the estimated variance due to study is now reported as $\hat{\sigma}_{s}$ (estimated $\sigma$ for study); this statistic also was divided by the dependent variable mean and multiplied by 100 to generate a CV equivalent for study.

\section{RESULTS}

Dietary variables, FA intakes, and duodenal flows of individual FA used in our analysis are reported in Table 2. Total FA flow through the duodenum was positively linearly related to total intake of FA $(P<0.0001$; Figure 1).

We initially evaluated all 61 treatments for apparent FA digestibility estimates (Table 3 ). We chose to compare all other FA to C18:0 as we considered C18:0 to be the most appropriate FA to compare with both $\mathrm{C} 16: 0$ and 18-carbon unsaturated FA. Digestibility was not different for C16:0 compared with C18:0 $(P=0.34)$. Additionally, C18:2 was not different than $\mathrm{C} 18: 0(P=$ 0.18). However, both $\mathrm{C} 18: 1$ and $\mathrm{C} 18: 3$ had increased digestibility compared with $\mathrm{C} 18: 0(P=0.002$ and $P=$ 0.03 , respectively).

Using apparent digestibilities of individual FA evaluated from studies that measured digestibility from the duodenum to the ileum we observed no differences between C16:0 and C18:0 ( $P=0.29$, Table 4). Digestibility estimates for $\mathrm{C} 18: 1$ and $\mathrm{C} 18: 3$ tended to be greater than $\mathrm{C} 18: 0$ (both $P=0.06$ ), but no difference was found between $\mathrm{C} 18: 2$ and $\mathrm{C} 18: 0(P=0.87)$. From studies that measured digestibility from the duodenum to feces, no differences were found between C16:0 and C18:0 $(P=0.10$, Table 5). However, all unsaturated FA had higher apparent digestibilities than $\mathrm{C} 18: 0(P=$ $0.0001, P=0.003$, and $P=0.003$ for C18:1, C18:2 and C18:3, respectively).

Last, individual FA digestibilities were determined for treatments that contained no supplemental fat (i.e., control treatments in the data set) to determine if digestibility differed as a result of fat supplementation (Table 6). Digestibility of C16:0 was similar to C18:0 $(P=0.24)$. Similarly, no difference was found in the digestibility of C18:1, C18:2, or C18:3 compared with C18:0 (all $P>0.50$ ).

Total FA duodenal flow reduced total apparent intestinal FA digestibility $(P=0.01$; Figure 2$)$. To deter- 
mine which variables affect individual FA digestibility, we developed best-fit equations from either duodenal (Table 7) or dietary variables (Table 8). Duodenal measurements were evaluated to determine postrumen factors that affect apparent FA digestibility (Table 7). For C16:0 digestibility, the linear and quadratic terms for flows of C16:0, C18:1, C18:2, and C18:3 were all included in the initial model. Adjusting C16:0 digestibility by study to account for the variation that exists between studies showed that C16:0 digestibility was not significantly affected by flow of C16:0 (range 23 to 526 $\mathrm{g} / \mathrm{d})$ through the duodenum $(P=0.74$; Figure 3$)$.

Variables that explained variation in apparent C18:0 digestibility included total flow of FA and the concentration of C18:0 and C18:1 flow through the duodenum. Figure 4 shows the effect of C18:0 flow through the duodenum (range 57 to $740 \mathrm{~g} / \mathrm{d}$ ) on C18:0 digestibility; when C18:0 through the duodenum increased, digestibility of C18:0 linearly decreased $(P<0.001$; Figure $4)$. The reduction in digestibility appears to occur regardless of type of fat supplemented. This relationship between C18:0 duodenal flow and C18:0 digestibility also remained when only considering control diets containing no supplemental fat (Figure 5). With flow of C18:0 reaching the duodenum ranging from approximately 50 to $450 \mathrm{~g} / \mathrm{d}$, the digestibility of C18:0 was linearly reduced $(P=0.05)$. Digestibility of total FA was negatively affected by increased intake of FA $(P$
$<0.001$; Figure 6). For example a 500-g increase in total FA intake reduced total FA digestibility by $4.25 \%$. The digestibility of C18:0 was the only FA digestibility estimate for which total flow of FA was significant and included in the best-fit equation (Table 7).

The digestibility of all unsaturated FA were negatively related to the concentration of C18:0 flow through the duodenum (Table 7). The digestibility of C18:1 (both cis and trans isomers included) was also explained by the quadratic coefficient for flow of C18:0, the linear and quadratic coefficients for flow of $\mathrm{C} 18: 2$ through the duodenum, and the linear coefficient for flow of C18:3. Digestibility of $\mathrm{C} 18: 2$ was explained by the quadratic flow of C18:0 and the flow of C18:1 and C18:2 through the duodenum. The variation in digestibility of C18:3 was explained by the linear and quadratic flow of $\mathrm{C} 16: 0$ in addition to the flow of C18:0. Total FA digestibility was explained by the total flow of FA in grams per day and the linear flow of C16:0 expressed as concentration of FA reaching the duodenum.

Prediction equations based on dietary variables are reported in Table 8. Digestibility of C16:0 was dependent on the concentration of C16:0 and C18:1 as a \% of diet DM. The DMI and forage concentration also significantly explained the variation in $\mathrm{C} 16: 0$ digestibility $(P<0.05)$. Total C16:0 intake $(\mathrm{DMI} \times$ dietary $\mathrm{C} 16: 0 \% \mathrm{DM})$, the interaction between DMI and forage concentration, and the interaction between dietary

Table 2. Minimum, maximum, mean, and standard deviation values of the data set

\begin{tabular}{|c|c|c|c|c|c|}
\hline Variable & $\mathrm{N}$ & Mean & Minimum & Maximum & $\mathrm{SD}$ \\
\hline Dietary FA, \% DM & 61 & 5.06 & 1.60 & 10.4 & 1.98 \\
\hline DMI, $\mathrm{kg} / \mathrm{d}$ & 61 & 17.9 & 8.44 & 26.9 & 4.56 \\
\hline Forage, \% DM & 61 & 52.4 & 35.0 & 65.0 & 8.21 \\
\hline \multicolumn{6}{|l|}{ FA intake, $g / d$} \\
\hline $\mathrm{C} 16: 0$ & 61 & 176 & 34.7 & 528 & 114 \\
\hline C18:0 & 61 & 47.0 & 4.20 & 147 & 37.0 \\
\hline C18:1 & 61 & 236 & 21.5 & 621 & 153 \\
\hline C18:2 & 61 & 243 & 34.4 & 676 & 137 \\
\hline $\mathrm{C} 18: 3$ & 56 & 77.6 & 8.90 & 480 & 95.3 \\
\hline \multicolumn{6}{|c|}{ FA intake, $g / 100 \mathrm{~g}$ of $\mathrm{FA}$} \\
\hline $\mathrm{C} 16: 0$ & 61 & 20.5 & 7.07 & 42.1 & 8.11 \\
\hline C18:0 & 61 & 5.24 & 2.03 & 12.9 & 3.33 \\
\hline C18:1 & 61 & 26.1 & 13.3 & 50.4 & 10.2 \\
\hline $\mathrm{C} 18: 2$ & 61 & 30.0 & 4.50 & 61.0 & 12.8 \\
\hline C18:3 & 56 & 9.89 & 2.01 & 49.6 & 9.89 \\
\hline \multicolumn{6}{|c|}{ FA duodenal flow, g/d } \\
\hline C16:0 & 61 & 161 & 23.4 & 526 & 97.5 \\
\hline C18:0 & 56 & 380 & 56.5 & 740 & 171 \\
\hline C18:1 & 56 & 149 & 17.5 & 485 & 102 \\
\hline C18:2 & 61 & 55.6 & 6.03 & 212 & 45.2 \\
\hline $\mathrm{C} 18: 3$ & 56 & 8.77 & 0.30 & 31.7 & 7.57 \\
\hline \multicolumn{6}{|c|}{ FA duodenal flow, $\mathrm{g} / 100 \mathrm{~g}$ of FA } \\
\hline C16:0 & 59 & 19.5 & 8.88 & 39.7 & 7.08 \\
\hline $\mathrm{C} 18: 0$ & 54 & 46.3 & 14.4 & 71.4 & 10.6 \\
\hline C18:1 & 54 & 16.4 & 6.43 & 38.7 & 7.50 \\
\hline C18:2 & 59 & 6.66 & 1.27 & 18.8 & 3.67 \\
\hline C18:3 & 54 & 1.10 & 0.07 & 3.01 & 0.75 \\
\hline
\end{tabular}


Table 3. Apparent intestinal digestibility estimates of individual FA from studies using either ileal or fecal collection methods in lactating dairy cattle

\begin{tabular}{lcccccc}
\hline FA & $\mathrm{n}$ & Estimate & SE & Lower limit $^{1}$ & Upper limit $^{1}$ & $P$-value \\
\hline $16: 0$ & 61 & 76.0 & 1.04 & 74.0 & 78.1 & 0.34 \\
18:0 & 61 & 73.3 & 2.68 & 68.0 & 78.5 & - \\
$18: 1$ & 56 & 81.6 & 0.57 & 80.5 & 82.7 & 0.002 \\
$18: 2$ & 61 & 77.7 & 1.92 & 73.9 & 81.5 & 0.18 \\
$18: 3$ & 48 & 79.2 & 0.59 & 78.0 & 81.3 & 0.03 \\
Total & 61 & 74.7 & 1.68 & 71.5 & 78.0 & 0.64 \\
\hline
\end{tabular}

${ }^{1}$ Lower and upper limit represent a $95 \%$ confidence interval.

${ }^{2} P$-value associated with comparing individual FA digestibility against C18:0.

C16:0\% DM by forage concentration were also significant. The fat type supplemented altered digestibility of C16:0, with calcium salts of FA-supplemented diets having higher digestibility and the control and wholeseeds-supplemented diets having the lowest digestibility for total C16:0.

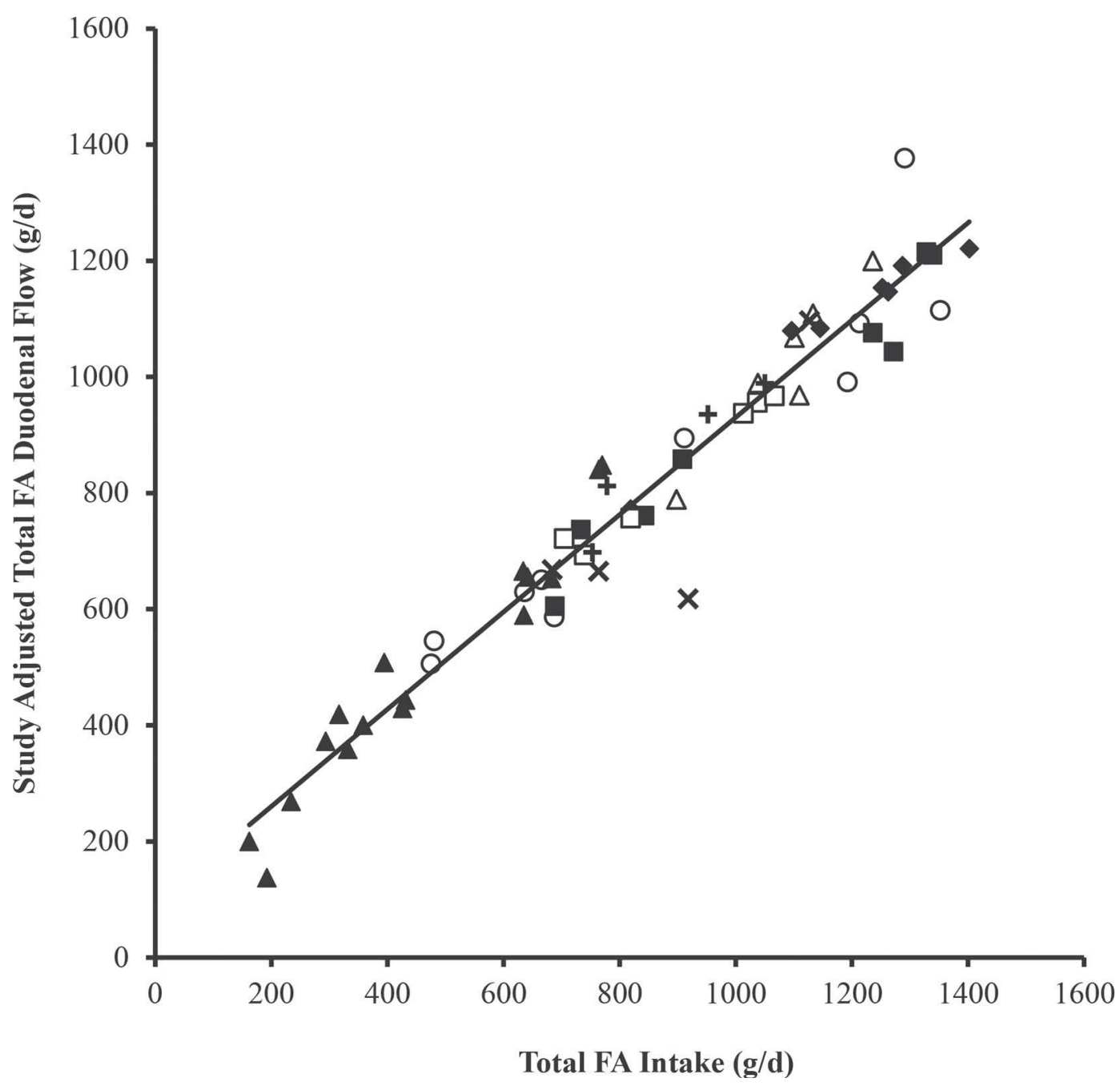

Figure 1. Relationship between study-adjusted total FA duodenal flow $(\mathrm{g} / \mathrm{d})$ and total FA intake (g/d) for 61 observations from 15 studies. Total FA duodenal flow $(\mathrm{g} / \mathrm{d})=92.89(\mathrm{SE}=29.01)+0.838(\mathrm{SE}=0.054) \times$ total FA intake $(\mathrm{g} / \mathrm{d}) ; P<0.001 ;$ intercept, $P=0.006$. Control treatments represented by $\mathbf{\Lambda}$; animal-vegetable fat treatments represented by ; calcium salt treatments represented by $\mathbf{\square}$; tallow treatments represented by $\bigcirc$; vegetable oil treatments represented by $\Delta$; seed meal treatments represented by $\square$; whole seed treatments represented by + ; and other treatments represented by $\times$. 
Table 4. Apparent intestinal digestibility estimates of individual FA from studies using ileal collection in lactating dairy cattle

\begin{tabular}{lcccccc}
\hline FA & $\mathrm{n}$ & Estimate & SE & Lower limit & Upper limit $^{1}$ & $P$-value \\
\hline $16: 0$ & 18 & 77.1 & 1.46 & 74.2 & 79.9 & 0.29 \\
$18: 0$ & 18 & 72.8 & 3.82 & 65.3 & 80.3 & - \\
$18: 1$ & 13 & 80.2 & 0.85 & 78.5 & 81.8 & 0.06 \\
$18: 2$ & 18 & 73.5 & 2.16 & 69.3 & 87.8 & 0.87 \\
$18: 3$ & 10 & 80.5 & 1.68 & 77.2 & 77.8 & 0.06 \\
Total & 18 & 74.5 & 1.44 & 71.7 & 0.68 \\
\hline
\end{tabular}

${ }^{1}$ Lower and upper limit represent a $95 \%$ confidence interval.

${ }^{2} P$-value associated with comparing individual FA digestibility against C18:0.

Apparent digestibility of $\mathrm{C} 18: 0$ was dependent on the concentration of $\mathrm{C} 18: 0, \mathrm{C} 18: 1$, and $\mathrm{C} 18: 2$ as a $\%$ of DM. Total C18:0 intake (DMI $\times$ dietary C18:0\%) also explained variation observed in C18:0 digestibility. Although DMI was not significant, the term remained in the model because of the significant interactions that contained DMI.

Apparent digestibility of C18:1 was affected by dietary concentration of $\mathrm{C} 18: 1$ as a $\%$ of $\mathrm{DM}$ and by the type of fat supplemented. Calcium salts of FA and vegetable oil-supplemented diets had higher digestibility estimates, whereas whole seed-supplemented diets had the lowest digestibility for total C18:1 reaching the duodenum. Digestibility of C18:2 was only significantly affected by the type of fat supplemented. Similarly to C18:1, calcium salts of FA and vegetable-oil-supplemented diets had the highest estimates, whereas wholeseed-supplemented diets had the lowest digestibility of the fat types analyzed. Digestibility estimates of C18:3 were affected by the dietary concentrations of C16:0 and the forage concentration of diets.

Total FA apparent digestibility was affected by the interaction between DMI and dietary fat concentration and by the type of fat supplemented. The variables DMI and dietary fat remained in the model because the interaction term was significant. Calcium salts and vegetable oil-supplemented diets had the highest estimates for total FA digestibility. The calcium salt FA treatments in the current data set included salts of palm FA and rapeseed FA.

\section{DISCUSSION}

Our data set contained studies with a wide range of dietary conditions and intakes of individual FA. We compared the digestibility of every FA to the digestibility of C18:0. The concentration of C18:0, regardless of degree of saturation of dietary fat type, typically represents the FA at largest concentrations leaving the rumen and available for absorption (Table 2). Additionally, C18:0 is a logical comparison for both C16:0, both being saturated, and for C18:1, C18:2, and C18:3 because of equal chain length. Although we observed significant differences between C18:0 and unsaturated FA using meta-analysis, the differences in digestibility estimates were modest. Comparison of digestibility estimates across different sites of collection (estimates from Tables 4 and 5) should only be made with caution because no study measured digestibility using both ileal and fecal collection; thus, study-adjusted digestibility estimates might not be independent from random effects among studies. The most valid way to evaluate differences is by comparing individual FA against C18:0 within site of collection. However, generation of bestfit equations showed that only C18:0 digestibility was significantly reduced as flow of total FA increased. Additionally, C18:0 concentration significantly negatively affected the apparent digestibility of all 18-carbon FA.

The positive linear relationship between intake of FA and duodenal flow of FA is similar to what has previously been reported in reviews by Doreau and Ferlay

Table 5. Apparent intestinal digestibility estimates of individual FA from studies using fecal collection in lactating dairy cattle

\begin{tabular}{lcccccc}
\hline FA & $\mathrm{n}$ & Estimate & SE & Lower limit $^{1}$ & Upper limit $^{1}$ & $P$-value \\
\hline $16: 0$ & 43 & 76.5 & 0.64 & 75.3 & 77.8 & 0.10 \\
$18: 0$ & 43 & 73.7 & 1.56 & 70.7 & 86.8 & 0.6 \\
$18: 1$ & 43 & 80.8 & 0.93 & 79.0 & 82.6 & 0.001 \\
$18: 2$ & 43 & 79.9 & 1.34 & 77.3 & 80.0 & 0.003 \\
$18: 3$ & 38 & 78.8 & 0.65 & 77.5 & 77.4 & 0.52 \\
Total & 43 & 75.0 & 1.24 & 72.6 & \\
\hline
\end{tabular}

${ }^{1}$ Lower and upper limit represent a $95 \%$ confidence interval.

${ }^{2} P$-value associated with comparing individual FA digestibility against C18:0. 
Table 6. Apparent intestinal digestibility estimates of individual FA from nonfat supplemented (control) treatments in lactating dairy cattle

\begin{tabular}{lcccccc}
\hline FA & $\mathrm{n}$ & Estimate & SE & Lower limit $^{1}$ & Upper limit $^{1}$ & $P$-value \\
\hline $16: 0$ & 16 & 76.7 & 1.88 & 73.0 & 80.4 & 0.24 \\
18:0 & 16 & 81.9 & 4.02 & 74.0 & 89.8 & - \\
18:1 & 15 & 82.3 & 1.31 & 79.7 & 84.9 & 0.93 \\
$18: 2$ & 16 & 77.3 & 5.90 & 65.7 & 88.8 & 0.52 \\
$18: 3$ & 13 & 79.5 & 1.24 & 77.1 & 81.9 & 0.57 \\
Total & 16 & 77.8 & 3.95 & 70.1 & 85.6 & 0.53 \\
\hline
\end{tabular}

${ }^{1}$ Lower and upper limit represent a $95 \%$ confidence interval.

${ }^{2} P$-value associated with comparing individual FA digestibility against C18:0.

(1994) and Doreau and Chilliard (1997) on a grams per kilogram of DM basis using results from cattle and sheep (measurements between duodenum and ileum or between duodenum and feces). Similar to our metaanalysis results, they reported no difference between C16:0 and C18:0 digestibility. However, contrary to our results for total FA and C18:0 digestibility being affected by duodenal flow, which was related to intake of 18-carbon FA, Doreau and Chilliard (1997) reported that on a grams per kilogram of DM basis intestinal digestibility of FA was not associated with FA intake. Glasser et al. (2008) generated equations to predict duodenal flow of 18-carbon FA using dietary variables from results with lactating and nonlactating cattle and sheep that reported duodenum to ileum FA digestibility. They reported that for all unsaturated 18-carbon
FA, absorption was a linear function of duodenal flow of FA (g/ $/ \mathrm{kg}$, DM basis). However, absorption of C18:0 plateaued at high duodenal flows of C18:0, indicating reduced digestibility at higher duodenal flow on a grams per kilogram of DM basis. Apparent 18-carbon FA digestibilities reported by Glasser et al. (2008) were in the same range $(\sim 70-82 \%)$ as what we observed; however, they reported individual estimates for specific isomers of unsaturated FA, whereas we combined all isomers into one estimate due to a limited number of observations accounting for individual 18-carbon isomers in lactating dairy cow studies.

The reduction in C18:0 digestibility with increasing flow through the duodenum is in agreement with results from individual studies that reported reductions in C18:0 digestibility in fat-supplemented diets

Table 7. Meta-regression for duodenal measurements to determine best-fit equations for individual FA intestinal digestibility coefficients (\%) in lactating dairy cattle

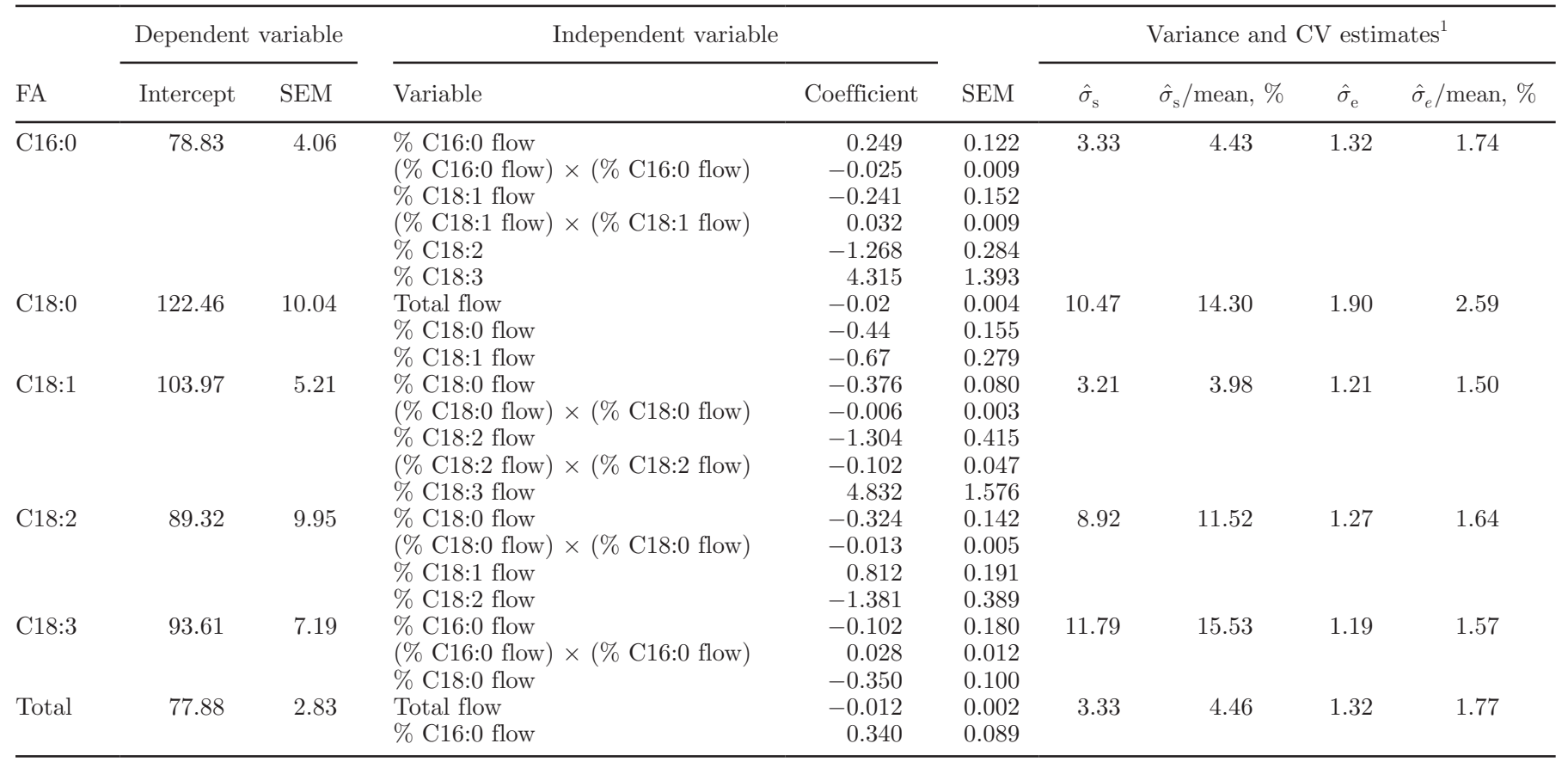

${ }^{1} \hat{\sigma}_{\mathrm{s}}=$ square root of the estimated study variance; $\hat{\sigma}_{\mathrm{e}}=$ square root of the estimated residual variance. 


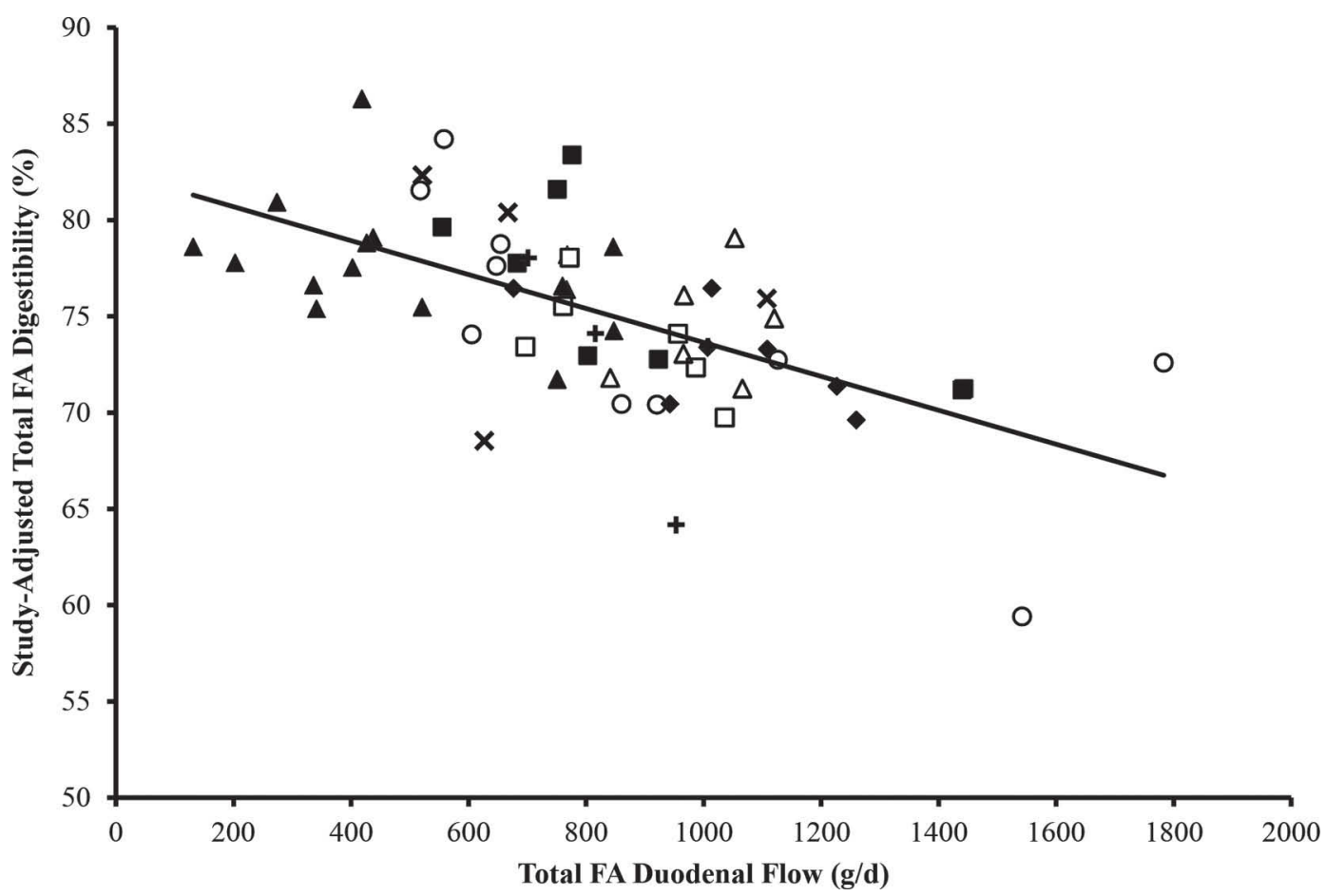

Figure 2. Relationship between study-adjusted total FA intestinal digestibility (\%) and total FA duodenal flow (g/d) for 61 observations from 15 studies. Total FA digestibility $(\%)=82.46(\mathrm{SE}=2.15)-0.0088(\mathrm{SE}=0.0031) \times$ total FA duodenal flow $(\mathrm{g} / \mathrm{d}) ; P=0.01 . \quad$ Control treatments represented by $\mathbf{\Lambda}$; animal-vegetable fat treatments represented by ; calcium salt treatments represented by $\mathbf{\square}$; tallow treatments represented by $\bigcirc$; vegetable oil treatments represented by $\Delta$; seed meal treatments represented by $\square$; whole seed treatments represented by + ; and other treatments represented by $\times$.

compared with control diets (e.g., Tice et al., 1994; Pantoja et al., 1996; Loor et al., 2002). In our data set, control diets with no added fat had C18:0 digestibility estimates that were equivalent to all other FA digestibility estimates (Table 6). Most likely, this is due to the reduced flow of C18:0 to the duodenum and adequate physiological capacity to emulsify and absorb 18:0. However, we still observed a reduction in C18:0 digestibility in the control diets as duodenal flow of C18:0 increased (Figure 5). A potential reason for the reduction in C18:0 digestibility as flow increases is if lysolecithin were limiting. Lysolecithin is an effective amphiphile for C18:0, increasing the flux of FA into micelles and therefore increasing absorption (Freeman, 1984). If C18:0 flow exceeded the capacity of either the lecithin in bile or the phospholipase excreted from the pancreas, digestibility of C18:0 may be reduced. Heath and Morris (1963) reported that FA absorption was almost nonexistent when bile secretions were blocked in ruminants and Jenkins and Fotouhi (1990) reported that feeding lecithin slightly improved postrumen FA digestibility in sheep. However, supplementing additional lysolecithin to dairy cows in a diet containing supplemental soybeans and soybean oil reduced milk fat yield compared with a diet containing no additional lysolecithin (Rico et al., 2014a). If additional lysolecithin increased uptake of C18:0 we might expect to see an increase in milk fat yield or an increase in C18:0 and cis-9 C18:1. Other mechanisms may be responsible for the reduction of digestibility of C18:0 as flow increased: for example, physical structure of the FA or its incorporation in microbial membranes (or both) affecting solubility, availability of absorption sites, or availability of FA within a fat supplement. Interestingly, Freeman (1969) observed a reduction in C18:0 incorporation into the micelle when $\mathrm{pH}>6.4$ in the presence of $1.0 \mathrm{mEq} / \mathrm{L}$ of calcium ions. Additional research to understand the observed reductions in C18:0 digestibility and how this may be overcome or improved is required.

Harrison and Leat (1972) used radiolabeled FA in sheep to determine the percent absorption and absorption rates between the small intestine and lymph fluid for individual FA. Compared with C18:0, C16:0 increased the rate of absorption and therefore the total percent of FA absorbed. Potentially, these differences in absorption between FA that only differ in chain-length are due to the increased ability of C16:0 to form micelles. Across our data set, we observed no effect of C16:0 flow on C16:0 digestibility; however, Piantoni et al. (2013) fed a 99\% pure C16:0 free FA supplement and reported 
Table 8. Meta-regression for dietary measurements to determine a best-fit equation for apparent intestinal digestibility of individual FA (\%) in lactating dairy cattle

\begin{tabular}{|c|c|c|c|c|c|c|c|c|c|}
\hline \multirow[b]{2}{*}{ FA } & \multicolumn{2}{|c|}{$\begin{array}{l}\text { Dependent } \\
\text { variable }\end{array}$} & \multicolumn{3}{|c|}{ Independent variable } & \multicolumn{4}{|c|}{ Variance and CV estimates $^{1}$} \\
\hline & Intercept & SEM & Variable & Coefficient & SEM & $\hat{\sigma}_{\mathrm{s}}$ & $\hat{\sigma}_{\mathrm{s}} /$ mean, $\%$ & $\hat{\sigma}_{\mathrm{e}}$ & $\hat{\sigma}_{\mathrm{e}} /$ mean, $\%$ \\
\hline $\mathrm{C} 16: 0$ & 105.98 & 8.69 & $\begin{array}{l}\text { Dietary C16:0 }(\% \mathrm{DM}) \\
\text { Dietary C18:1 }(\% \mathrm{DM}) \\
\text { DMI }(\mathrm{kg} / \mathrm{d}) \\
\text { DMI } \times \text { dietary C16:0 }(\% \mathrm{DM}) \\
\text { Forage \% } \\
\text { DMI } \times \text { forage } \% \\
\text { Dietary C16:0 }(\% \mathrm{DM}) \times \text { forage } \\
\% \\
\text { Fat type }{ }^{2} \\
\text { AVF } \\
\text { Ca salts } \\
\text { Control } \\
\text { Other } \\
\text { Seed meal } \\
\text { Tallow } \\
\text { Vegetable oil } \\
\text { Whole seeds }\end{array}$ & $\begin{array}{l}-4.197 \\
-3.794 \\
-0.419 \\
-1.208 \\
-0.271 \\
-0.102 \\
-0.692\end{array}$ & $\begin{array}{l}2.09 \\
3.12 \\
2.07 \\
2.65 \\
2.45 \\
2.18 \\
1.97 \\
3.29\end{array}$ & 5.07 & 6.69 & 1.15 & 1.52 \\
\hline C18:1 & 83.08 & 2.06 & $\begin{array}{l}\text { Dietary C18:1 }(\% \mathrm{DM}) \\
\text { Fat type } \\
\text { AVF } \\
\text { Ca salts } \\
\text { Control } \\
\text { Other } \\
\text { Seed meal } \\
\text { Tallow } \\
\text { Vegetable oil } \\
\text { Whole seed }\end{array}$ & $\begin{array}{l}-2.544 \\
82.67 \\
86.85 \\
78.67 \\
83.69 \\
75.52 \\
77.75 \\
85.42 \\
64.18\end{array}$ & $\begin{array}{l}0.768 \\
2.33 \\
1.98 \\
1.90 \\
2.36 \\
2.54 \\
2.56 \\
1.96 \\
4.48\end{array}$ & 5.28 & 6.56 & 1.12 & 1.39 \\
\hline C18:3 & 85.97 & 5.40 & $\begin{array}{l}\text { Dietary C16:0\% DM } \\
\text { Forage } \%\end{array}$ & $\begin{array}{r}3.021 \\
-0.238\end{array}$ & $\begin{array}{l}1.491 \\
0.095\end{array}$ & 5.90 & 7.78 & 1.39 & 1.83 \\
\hline Total & 74.06 & 8.19 & $\begin{array}{l}\text { DMI } \\
\text { Dietary fat }(\% \text { DM }) \\
\text { DMI } \times \text { dietary fat }(\% \text { DM }) \\
\text { Fat type } \\
\text { AVF } \\
\text { Ca salts } \\
\text { Control } \\
\text { Other } \\
\text { Seed meal } \\
\text { Tallow } \\
\text { Vegetable oil } \\
\text { Whole seeds }\end{array}$ & $\begin{array}{r}0.741 \\
1.681 \\
-0.284 \\
\\
77.46 \\
80.97 \\
70.89 \\
76.73 \\
72.11 \\
74.11 \\
80.44 \\
72.58\end{array}$ & $\begin{array}{l}2.412 \\
2.387 \\
2.500 \\
3.445 \\
2.509 \\
2.327 \\
2.678 \\
2.702\end{array}$ & 7.49 & 10.03 & 1.05 & 1.41 \\
\hline
\end{tabular}

${ }^{1} \hat{\sigma}_{\mathrm{s}}=$ square root of the estimated study variance; $\hat{\sigma}_{\mathrm{e}}=$ square root of the estimated residual variance.

${ }^{2}$ Coefficients and standard errors for the class variable (fat type) represent the least squares means for apparent digestibility of individual FA when specific fat types were supplemented. AVF = animal-vegetable fat. 


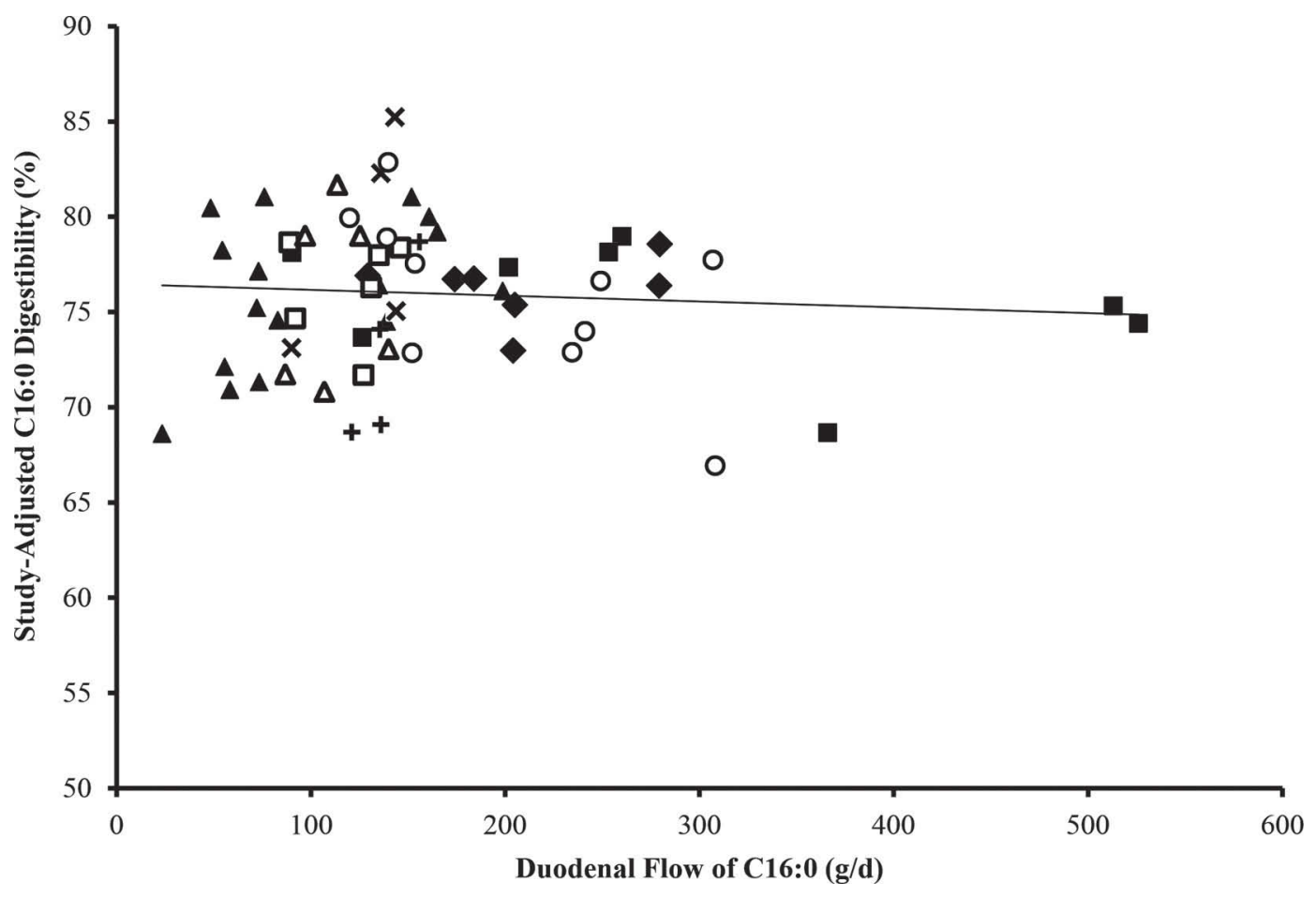

Figure 3. Relationship between study-adjusted C16:0 intestinal digestibility and duodenal flow of C16:0. Study-adjusted C16:0 digestibility $(\%)=76.46(\mathrm{SE}=1.83)-0.0030(\mathrm{SE}=0.0090) \times$ duodenal flow of $\mathrm{C} 16: 0(\mathrm{~g} / \mathrm{d}) ; P=0.74$. Control treatments represented by $\mathbf{\Delta} ;$ animal-vegetable fat treatments represented by $\checkmark$; calcium salt treatments represented by $\mathbf{\square}$; tallow treatments represented by $\bigcirc$; vegetable oil treatments represented by $\Delta$; seed meal treatments represented by $\square$; whole seed treatments represented by + ; and other treatments represented by $\times$.

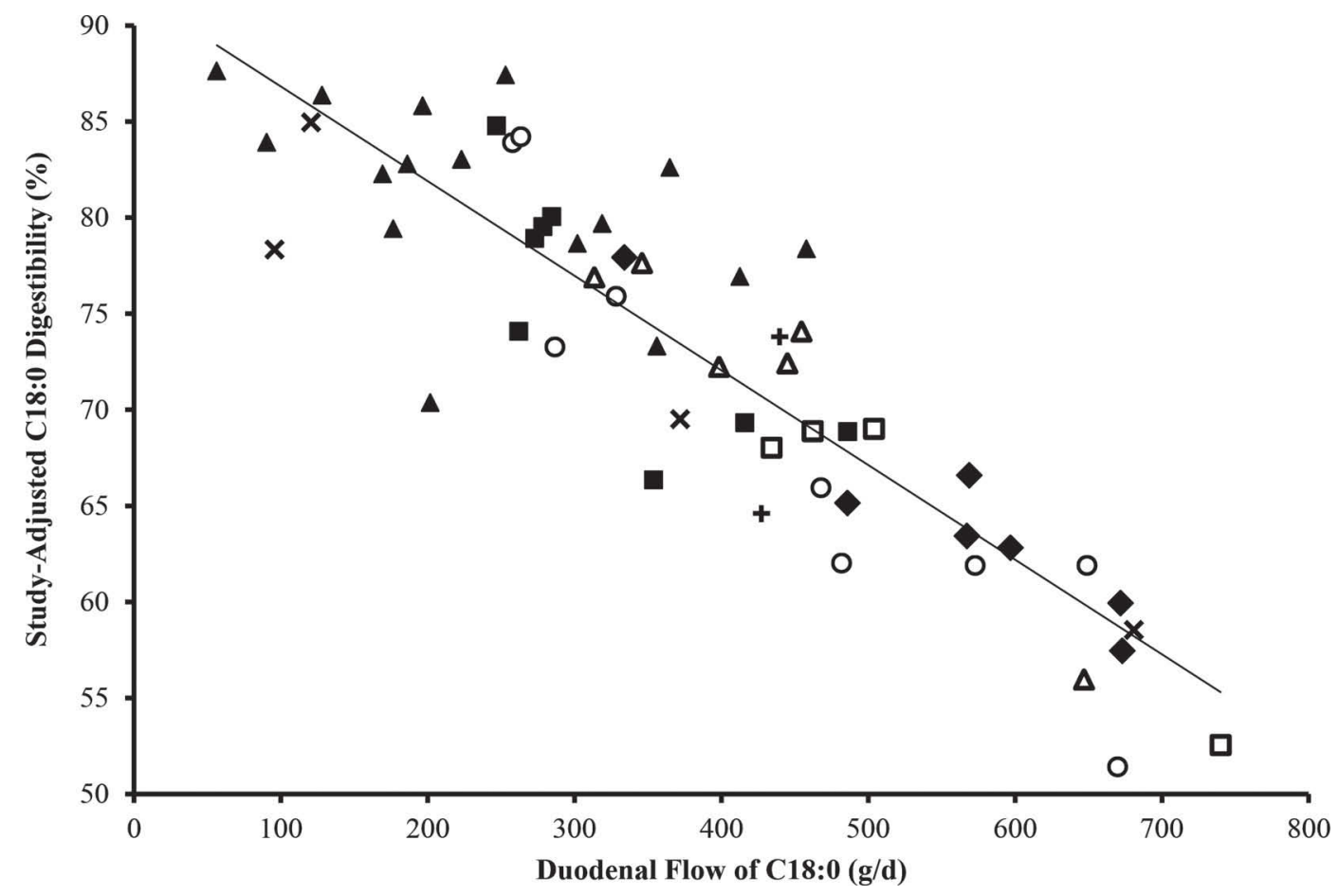

Figure 4. Relationship between study-adjusted C18:0 intestinal digestibility and duodenal flow of C18:0. Study-adjusted C18:0 digestibility $(\%)=91.76(\mathrm{SE}=1.98)-0.0493(\mathrm{SE}=0.0098) \times$ duodenal flow of $\mathrm{C} 18: 0(\mathrm{~g} / \mathrm{d}) ; P<0.001$. Control treatments represented by $\boldsymbol{\Delta} ;$ animal-vegetable fat treatments represented by $\bullet$; calcium salt treatments represented by $\mathbf{\square}$; tallow treatments represented by $\bigcirc$; vegetable oil treatments represented by $\Delta$; seed meal treatments represented by $\square$; whole seed treatments represented by + ; and other treatments represented by $\times$. 


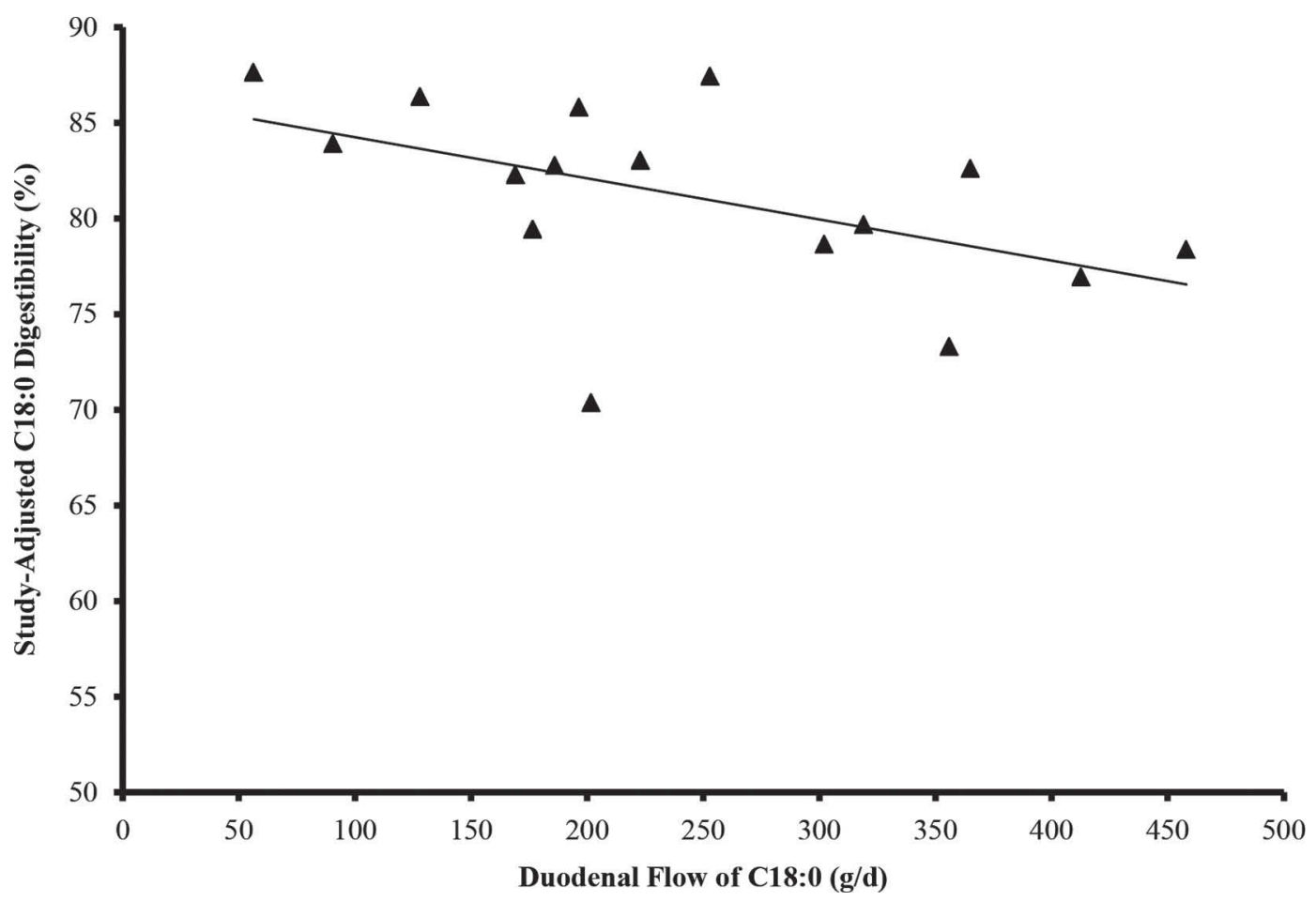

Figure 5. Relationship between study-adjusted C18:0 intestinal digestibility and duodenal flow of C18:0 for control diets. Study-adjusted C18:0 digestibility $(\%)=86.41(\mathrm{SE}=2.62)-0.0215(\mathrm{SE}=0.0098) \times$ duodenal flow of $\mathrm{C} 18: 0(\mathrm{~g} / \mathrm{d}) ; P=0.05$.

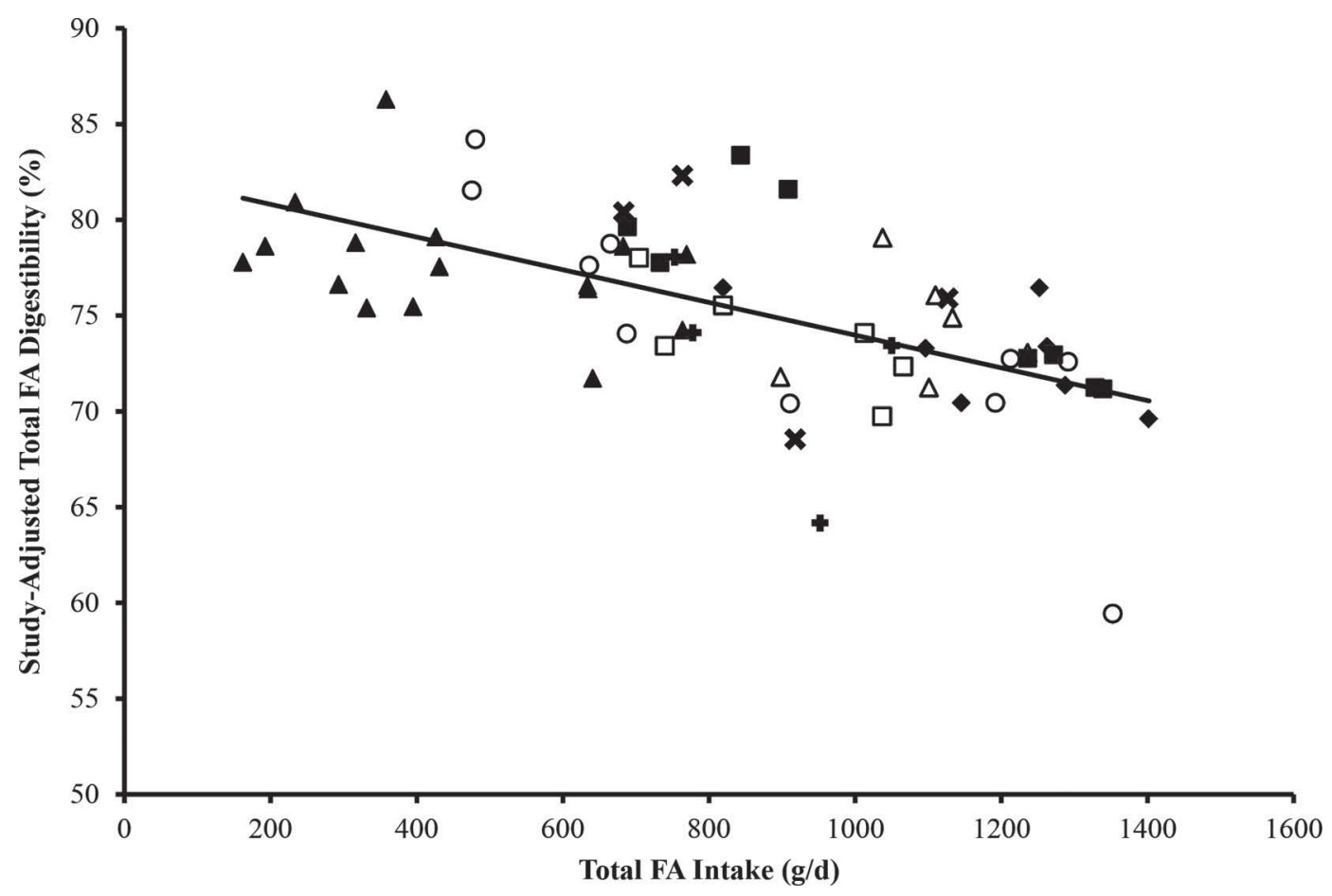

Figure 6. Relationship between study-adjusted total FA intestinal digestibility and total FA intake. Study-adjusted total FA digestibility (\%) $=82.70(\mathrm{SE}=2.03)-0.00848(\mathrm{SE}=0.00274) \times$ total FA intake $(\mathrm{g} / \mathrm{d}) ; P<0.001$. Control treatments represented by $\mathbf{\Delta} ;$ animal-vegetable fat treatments represented by $\bullet$ calcium salt treatments represented by $\mathbf{\square}$; tallow treatments represented by $\bigcirc$; vegetable oil treatments represented by $\Delta$; seed meal treatments represented by $\square$; whole seed treatments represented by + ; and other treatments represented by $\times$. 
a reduction in 16-carbon total-tract digestibility, potentially due to the physical size of the fat supplement reducing solubilization in the small intestine. Interestingly, total FA digestibility was negatively affected by flow of total FA through the duodenum and positively affected by the concentration of $\mathrm{C} 16: 0$ reaching the duodenum. This indicates that not only total FA flow but also the profile of FA entering the duodenum are important factors affecting FA digestibility. Further research is required to determine if $\mathrm{C} 16: 0$ digestibility is affected with increased duodenal flow, especially given the increased use of C16:0-enriched fat supplements in dairy cattle diets.

The type of fat included in the diet affected digestibility for 3 out of the 5 individual FA reported (C16:0, C18:1, and C18:2) and for total FA. When whole seeds were fed we observed reduced individual FA digestibility, whereas when calcium salts of FA and vegetable oils and were fed, we observed increased individual FA digestibility. A possible reason for these discrepancies in digestibility might be availability of the FA when reaching the small intestine. Calcium salts of FA and vegetable oils are readily available for emulsification and absorption in the small intestine, whereas the FA in whole seeds is contained within the hard seed coat that is resistant to degradation in the rumen (Mohamed et al., 1988; Reddy et al., 1994). Although whole seeds may limit the negative effects of unsaturated FA in the rumen, their reduced digestibility in the small intestine might limit their effectiveness as a fat source to include in lactating dairy cattle diets.

Using meta-analysis limits the scope of interpretation of results because not all of the studies were performed the same way with cows of the same genetic potential, diets, fat types, stage of lactation, and so on. The method of collection and analysis were different, so the results have to be considered in context. However, by including studies across a wide range of feeding strategies, we can be more confident that the mean response is representative of what would actually occur in a future study as long as the data set is reasonably balanced and the random effect of study averages such sources of variation to decrease their potential bias (St-Pierre, 2001). A limited number of studies have reported individual FA digestibilities in lactating dairy cattle. Only one of these studies reported both duodenum to ileum and duodenum to fecal digestibility to compare the 2 methods for determining FA digestibility (Pantoja et al., 1996); however, this study did not report the standard error for both methods of digestibility estimates. Therefore, no inferences can be made comparing method of calculating digestibility between fecal and ileal collection.
Our meta-analysis results indicate the presence of minimal differences in the digestibility of individual FA. However, these represent the weighted mean value that masked important differences in apparent digestibility related to increased flow of FA to the small intestine. Further insight on both dietary and duodenal factors that affect individual FA digestibility was gained using meta-regression and plotting FA digestibility by duodenal flows of individual FA. For example, C18:0 digestibility was similar to other FA at lower duodenal flow but markedly decreased with increasing flow that affected overall total FA digestibility. For fat-supplemented diets, diets high in FA, or both, the reduction in total FA digestibility should be considered when predicting available energy for the dairy cow. Characteristics of the diet, type of fat supplemented, and amount of individual FA reaching the duodenum may all affect individual FA digestibility estimates.

Increasing duodenal flow of C18:0 reduced the digestibility of C18:0 when analyzing all of the treatments as well as control (non fat-supplemented) treatments. However, our analysis is based on associations and should be followed up by direct hypothesis testing. For example, studies providing additional lysolecithin to C18:0-enriched fat supplemented diets would provide further insight. Additionally, rumen protection methods for FA designed to increase the flow of unsaturated FA may have benefits to the cow in terms of providing essential FA as well as increasing the efficiency of digestion from feeding a fat supplement. That C16:0 did not have a reduction in digestibility over a wide range of duodenal flows probably indicates unique properties and potential uses for increasing C16:0 inclusion in lactating cattle diets, provided the characteristics of the fat supplement allow for adequate intestinal absorption.

Although we demonstrated that individual FA digestibility is dependent on several dietary and duodenal variables, the differences in FA digestibility should be considered in context. The amount of FA that are included in the diet is relatively small for lactating dairy cattle, and changes in FA digestibility therefore may have minimal effects on overall DM digestibility and digestible energy intake. Even significant reductions in individual FA digestibility estimates may have little effect on reducing total DM digestibility compared with reductions in digestibility of more abundant feed ingredients. Potentially of greater importance, fat supplements may affect DMI (Allen, 2000) and digestibility of other nutrients (Palmquist, 1991). Changes in intake and digestibility of other nutrients due to fat supplementation may affect, positively or negatively, digestible energy available for milk production, body reserves, or both. 


\section{CONCLUSIONS}

Digestion and metabolism of FA in ruminants is complex and dependent on coordination of several processes. We observed minimal differences in FA digestibility using meta-analysis techniques to compile results from 15 studies feeding a variety of fat supplements. In control diets that contained no additional fat, no differences were observed in the digestibility of individual FA. However, generation of best-fit equations and study-adjusted plots indicate that C18:0 flow through the duodenum negatively affects digestibility of several FA. The most severe reduction in digestibility for C18:0 is observed at high concentrations of C18:0 flow through the duodenum. The mechanisms that reduce C18:0 absorption when at high concentrations are unknown and warrant further investigation.

\section{ACKNOWLEDGMENTS}

We acknowledge Gerald Poppy (Packerland Whey Products Inc.) and William Sanchez (Diamond V Inc.) for their assistance with analyzing this data set and helpful discussions. Research was supported by Michigan State University AgBioResearch and state and federal funds appropriated to the Ohio Agricultural Research and Development Center, The Ohio State University.

\section{REFERENCES}

Abayasekara, D. R., and D. C. Wathes. 1999. Effects of altering dietary fatty acid composition on prostaglandin synthesis and fertility. Prostaglandins Leukot. Essent. Fatty Acids 61:275-287.

Allen, M. S. 2000. Effects of diet on short-term regulation of feed intake by lactating dairy cattle. J. Dairy Sci. 83:1598-1624.

Ambrose, D. J., J. P. Kastelic, R. Corbett, P. A. Pitney, H. V. Petit, J. A. Small, and P. Zalkovic. 2006. Lower pregnancy losses in lactating dairy cows fed a diet enriched in alpha-linolenic acid. J. Dairy Sci. 89:3066-3074

Andrews, R. J., and D. Lewis. 1970. The utilization of dietary fats by ruminants. II. The effect of fatty acid chain length and unsaturation on digestibility. J. Agric. Sci. 75:55-60.

Avila, C. D., E. J. DePeters, H. Perez-Monti, S. J. Taylor, and R. A. Zinn. 2000. Influences of saturation ratio of supplemental dietary fat on digestion and milk yield in dairy cows. J. Dairy Sci. $83: 1505-1519$

Bauchart, D. 1993. Lipid absorption and transport in ruminants. J. Dairy Sci. 76:3864-3881.

Bauchart, D., M. Doreau, and A. Kindler. 1987. Effect of fat and lactose supplementation on digestion in dairy cows. 2. Long-chain fatty acids. J. Dairy Sci. 70:71-80.

Borenstein, M., L. V. Hedges, J. P. T. Higgins, and H. R. Rothstein. 2009. Introduction to Meta-Analysis. John Wiley \& Sons Ltd. West Sussex, UK

Chilliard, Y. 1993. Dietary fat and adipose tissue metabolism in ruminants, pigs, and rodents: A review. J. Dairy Sci. 76:3897-3931.

Christensen, R. A., J. H. Clark, J. K. Drackley, and S. A. Blum. 1998 Fatty acid flow to the duodenum and in milk from cows fed diets that contained fat and nicotinic acid. J. Dairy Sci. 81:1078-1088.
Doreau, M., and Y. Chilliard. 1997. Digestion and metabolism of dietary fat in farm animals. Br. J. Nutr. 78:S15-S35.

Doreau, M., and A. Ferlay. 1994. Digestion and utilization of fattyacids by ruminants. Anim. Feed Sci. Technol. 45:379-396.

Elliott, J. P., J. K. Drackley, and D. J. Weigel. 1996. Digestibility and effects of hydrogenated palm fatty acid distillate in lactating dairy cows. J. Dairy Sci. 79:1031-1039.

Enjalbert, F., M. C. Nicot, C. Bayourthe, M. Vernay, and R. Moncoulon. 1997. Effects of dietary calcium soaps of unsaturated fatty acids on digestion, milk composition and physical properties of butter. J. Dairy Res. 64:181-195.

Ferlay, A., J. Chabrot, Y. Elmeddah, and M. Doreau. 1993. Ruminal lipid balance and intestinal digestion of dairy cows fed calcium salts of rapeseed oil fatty acids and rapeseed oil. J. Anim. Sci. $71: 2237-2245$.

Firkins, J.L., M.L. Eastridge, N.R. St-Pierre, and S.M. Noftsger. 2001. Effects of grain variability and processing on starch utilization by lactating dairy cattle. J. Anim. Sci. 79(E-Suppl.):E218-E238.

Freeman, C. P. 1969. Properties of fatty acids in dispersions of emulsified lipid and bile salt and the significance of these properties in fat absorption in the pig and the sheep. Br. J. Nutr. 23:249-263.

Freeman, C. P. 1984. Digestion, absorption and transport of fatsNon-ruminant animals. Pages 105-122 in Fats in Animal Nutrition. Butterworths, London, UK.

Glasser, F., P. Schmidely, D. Sauvant, and M. Doreau. 2008. Digestion of fatty acids in ruminants: A meta-analysis of flows and variation factors: 2. C18 fatty acids. Animal 2:691-704.

Harrison, F. A., and W. M. F. Leat. 1972. Absorption of palmitic, stearic, and oleic acids in the sheep in the presence or absence of bile and/or pancreatic juice. J. Physiol. 225:565-576.

Harrison, F. A., and W. M. F. Leat. 1975. Digestion and absorption of lipids in non-ruminant and ruminant animals: A comparison. Proc. Nutr. Soc. 34:203-210.

Heath, T. J., and B. Morris. 1963. The role of bile and pancreatic juice in the absorption of fat in ewes and lambs. Br. J. Nutr. 17:465-473.

Jenkins, T. C. 1993. Lipid metabolism in the rumen. J. Dairy Sci. $76: 3851-3863$

Jenkins, T. C., and N. Fotouhi. 1990. Effects of lecithin and corn oil on site of digestion, ruminal fermentation and microbial protein synthesis in sheep. J. Anim. Sci. 68:460-466.

Jenkins, T. C., and B. F. Jenny. 1989. Effect of hydrogenated fat on feed intake, nutrient digestion, and lactation performance of dairy cows. J. Dairy Sci. 72:2316-2324

Jenkins, T. C., R. J. Wallace, P. J. Moate, and E. E. Mosley. 2008 Board-invited review: Recent advances in biohydrogenation of unsaturated fatty acids within the rumen microbial ecosystem. J. Anim. Sci. 86:397-412.

Klusmeyer, T. H., G. L. Lynch, J. H. Clark, and D. R. Nelson. 1991. Effects of calcium salts of fatty acids and proportion of forage in diet on ruminal fermentation and nutrient flow to duodenum of cows. J. Dairy Sci. 74:2220-2232.

Loor, J. J., M. Doreau, J. M. Chardigny, A. Ollier, J. L. Sebedio, and Y. Chilliard. 2005. Effects of ruminal or duodenal supply of fish oil on milk fat secretion and profiles of trans-fatty acids and conjugated linoleic acid isomers in dairy cows fed maize silage. Anim. Feed Sci. Technol. 119:227-246.

Loor, J. J., J. H. Herbein, and T. C. Jenkins. 2002. Nutrient digestion, biohydrogenation, and fatty acid profiles in blood plasma and milk fat from lactating Holstein cows fed canola oil or canolamide. Anim. Feed Sci. Technol. 97:65-82

Loor, J. J., K. Ueda, A. Ferlay, Y. Chilliard, and M. Doreau. 2004 Biohydrogenation, duodenal flow, and intestinal digestibility of trans fatty acids and conjugated linoleic acids in response to dietary forage:concentrate ratio and linseed oil in dairy cows. J. Dairy Sci. 87:2472-2485.

Maia, M. R., L. C. Chaudhary, C. S. Bestwick, A. J. Richardson, N. McKain, T. R. Larson, I. A. Graham, and R. J. Wallace. 2010 Toxicity of unsaturated fatty acids to the biohydrogenating ruminal bacterium, Butyrivibrio fibrisolvens. BMC Microbiol. 10:52. 
Mohamed, O. E., L. D. Satter, R. R. Grummer, and F. R. Ehle. 1988. Influence of dietary cottonseed and soybean on milk production and composition. J. Dairy Sci. 71:2677-2688.

Moore, J. H., and W. W. Christie. 1984. Digestion, absorption and transport of fats in ruminant animals. Pages 123-149 in Fats in Animal Nutrition. Butterworths, London, UK.

Murphy, M., P. Uden, D. L. Palmquist, and H. Wiktorsson. 1987. Rumen and total diet digestibilities in lactating cows fed diets containing full-fat rapeseed. J. Dairy Sci. 70:1572-1582.

Noble, R. C. 1981. Digestion, transport and absorption of lipids. In W. W. Christie (Ed.) Lipid Metabolism in Ruminant Animals. pp. 57-93. Pergamon Press Ltd. Oxford, UK.

Ohajuruka, O. A., Z. Wu, and D. L. Palmquist. 1991. Ruminal metabolism, fiber, and protein digestion by lactating cows fed calcium soap or animal-vegetable fat. J. Dairy Sci. 74:2601-2609.

Oldick, B. S., J. L. Firkins, and N. R. St-Pierre. 1999. Estimation of microbial nitrogen flow to the duodenum of cattle based on dry matter intake and diet composition. J. Dairy Sci. 82:1497-1511.

Palmquist, D. L. 1991. Influence of source and amount of dietary fat on digestibility in lactating cows. J. Dairy Sci. 74:1354-1360.

Pantoja, J., J. L. Firkins, and M. L. Eastridge. 1996. Fatty acid digestibility and lactation performance by dairy cows fed fats varying in degree of saturation and different fiber sources. J. Dairy Sci. 79:429-437.

Piantoni, P., A. L. Lock, and M. S. Allen. 2013. Palmitic acid increased yields of milk and milk fat and nutrient digestibility across production level of lactating cows. J. Dairy Sci. 96:7143-7154.

Pires, A. V., M. L. Eastridge, J. L. Firkins, and Y. C. Lin. 1997. Effects of heat treatment and physical processing of cottonseed on nutrient digestibility and production performance by lactating cows. J. Dairy Sci. 80:1685-1694.

Reddy, P. V., J. L. Morrill, and T. G. Nagaraja. 1994. Release of free fatty acids from raw or processed soybeans and subsequent effects on fiber digestibilities. J. Dairy Sci. 77:3410-3416.
Rico, D. E., J. Y. Ying, and K. J. Harvatine. 2014a. Effects of lysolecithin on milk fat synthesis and milk fatty acid profile of cow fed diets differing in fiber and unsaturated fatty acid concentration. J. Anim. Sci. 92(E-Suppl.):1843 (Abstr.)

Rico, J. E., M. S. Allen, and A. L. Lock. 2014b. Compared with stearic acid, palmitic acid increased the yield of milk fat and improved feed efficiency across production level of cows. J. Dairy Sci. 97:1057-1066.

St-Pierre, N. R. 2001. Invited review: Integrating quantitative findings from multiple studies using mixed model methodology. J. Dairy Sci. 84:741-755.

St-Pierre, N. R., and D. Glamocic. 2000. Estimating unit costs of nutrients from market prices of feedstuffs. J. Dairy Sci. 83:1402-1411.

Steele, W., and J. H. Moore. 1968. The digestibility coefficients of myristic, palmitic and stearic acids in the diet of sheep. J. Dairy Res. 35:371-376.

Tice, E. M., M. L. Eastridge, and J. L. Firkins. 1994. Raw soybeans and roasted soybeans of different particle sizes. 2. Fatty acid utilization by lactating cows. J. Dairy Sci. 77:166-180.

Weisbjerg, M. R. C. F. Borsting, and T. Hvelplund. 1992. Fatty acid metabolism in the digestive tract of lactating cows fed tallow in increasing amounts at two feed levels. Acta. Agric. Scand. Anim. Sci. 42:106-114.

Weiss, W. P., and D. J. Wyatt. 2004. Digestible energy values of diets with different fat supplements when fed to lactating dairy cows. J. Dairy Sci. 87:1446-1454.

Wu, Z., O. A. Ohajuruka, and D. L. Palmquist. 1991. Ruminal synthesis, biohydrogenation, and digestibility of fatty acids by dairy cows. J. Dairy Sci. 74:3025-3034. 